\title{
Caffeine Treatment for Apnea of Prematurity and the Influence on Dose-Dependent Postnatal Weight Gain Observed Over 15 Years
}

\author{
Roy K. Philip, FRCPI, FRCPCH, FJFICMI, MD, MBA, ${ }^{1,2}$ Abu Ismail, MRCPI, MRCPS, DCH, ${ }^{1}$ \\ Bernadette Murphy, MSc, MPSI, ${ }^{3}$ Adnan Mirza, MRCPCH, DCH, FRCPI, ${ }^{1}$ \\ Collette Quinn, C-NEO, ${ }^{4}$ and Margo Dunworth, C-NEO ${ }^{4}$
}

Background and Aim: To analyze the influence on weight gain of infants exposed to two dosage regimens of oral caffeine citrate (CC) for apnea of prematurity.

Methods: Retrospective descriptive observational study of an eligible very low birth weight cohort over a 15-year period in an Irish University hospital. Data were analyzed between two distinct postnatal ages: 14-28 and 29-56 days.

Results: During the 15-year study, 457 infants were prescribed caffeine. Among the 14-28-day group, after applying exclusion criteria, 418 infants qualified. Two hundred forty-eight infants received $5 \mathrm{mg} /(\mathrm{kg} \cdot$ day) and 170 received $10 \mathrm{mg} /(\mathrm{kg} \cdot$ day) of CC. Among the 29-56-day group, 362 infants were identified and after applying exclusions, 332 fulfilled entry criteria [214 on $5 \mathrm{mg} /(\mathrm{kg} \cdot$ day $)$ and $118 \mathrm{on} 10 \mathrm{mg} /(\mathrm{kg} \cdot$ day $)$ regimen]. Baseline characteristics of infants were comparable between groups without statistically significant differences. Mean daily weight gain (MDWG) in grams from day 14 to 28 showed a higher rate of increase for the $5 \mathrm{mg} /(\mathrm{kg} \cdot$ day) group compared with the $10 \mathrm{mg} /(\mathrm{kg} \cdot$ day) group $(17.2 \pm 12 \mathrm{~g}$ vs. $13.0 \pm 10.2 \mathrm{~g}$ [ $p=0.04])$. From day 29 to 56, also MDWG was higher among infants on $5 \mathrm{mg} /(\mathrm{kg} \cdot$ day $)$ of CC compared with $10 \mathrm{mg} /(\mathrm{kg} \cdot$ day) group $(15.6 \pm 10.8 \mathrm{~g}$ vs. $10.2 \pm 9.8 \mathrm{~g}[p=0.011])$.

Conclusion: While a variety of measures are optimized to promote postnatal weight gain of premature infants close to an ideal intrauterine growth curve, not paying sufficient attention to one of the most widely used catabolic agents in neonatology is questionable and warrants vigilance. Additional nutritional measures could be offered to those with prolonged caffeine exposure.

Keywords: neonatal intensive care unit, caffeine citrate, apnea of prematurity, very low birth weight infants, methylxanthines, neonatal nutrition

\section{Introduction}

A PNEA OF PREMATURITY (AOP) is defined as the cessation of spontaneous breathing by a premature infant lasting for more than 20 seconds and/or accompanied by hypoxia or bradycardia. ${ }^{1}$ Caffeine citrate (CC) is the commonest methylxanthine universally used in the management of AOP, which occurs in about $85 \%$ of infants born at less than 34 weeks of gestation. ${ }^{2}$ It has been the mainstay of pharmacologic treatment of apnea of AOP for over 30 years and is often prescribed for very premature infants until they reach a postmenstrual age of 32-34 weeks. ${ }^{3,4}$ Caffeine therapy for AOP has also been shown to reduce the rate of bronchopulmonary dysplasia and improves the rate of survival of very low birth weight (VLBW) infants without neurodevelopmental disability at 18-21 months. ${ }^{5,6}$ Caffeine is one of the most prescribed drugs in the current neonatal practice. Its efficacy,

\footnotetext{
${ }^{1}$ Division of Neonatology, Department of Paediatrics, University Maternity Hospital Limerick (UMHL), Limerick, Ireland.

${ }^{2}$ Graduate Entry Medical School (GEMS), University of Limerick, Limerick, Ireland.

${ }^{3}$ Department of Pharmacy, University Hospital Limerick (UHL), Limerick, Ireland.

${ }^{4}$ Midwifery and Neonatal Nursing, University Maternity Hospital Limerick (UMHL), Limerick, Ireland.

(c) Roy K. Philip et al. 2018; Published by Mary Ann Liebert, Inc. This Open Access article is distributed under the terms of the Creative Commons Attribution Noncommercial License (http//creativecommons.org/licenses/by-nc/4.0) which permits any noncommercial use, distribution, and reproduction in any medium, provided the original author(s) and the source are cited.
} 
tolerability, wide therapeutic index, and safety margin have made it the drug of choice for AOP and is often used cumulatively for many weeks with potential catabolic effects that could impact on the initial weight gain of this vulnerable population. ${ }^{7}$

Effects of caffeine intake during pregnancy were analyzed by the CARE Study Group and highlighted the association of fetal growth restriction to caffeine consumption during pregnancy. ${ }^{8}$ Their observation, along with similar findings from previous studies, suggests that fetal growth restriction secondary to high-dose maternal caffeine exposure is consistent across all trimesters. ${ }^{8,9}$ An incremental intake of caffeine during pregnancy was reported with LBW in $7 \%$ and small for gestational age (SGA) in $10 \% .{ }^{10}$ Even though 18-21-month follow-up of caffeine-exposed infants for the treatment of AOP did not show reduction in weight or head circumference, somatic effect of dose- and duration-specific exposure during the neonatal period is not ascertained.

Caffeine readily crosses the blood/brain barrier and is a central nervous system stimulant. The principal mode of action is as an antagonist of adenosine receptors, which are $G$ protein-coupled receptors. ${ }^{11,12}$ Caffeine is a competitive inhibitor of cAMP-phosphodiesterase enzyme, which converts cyclic AMP to its noncyclic form, thus allowing cAMP to build up in cells. Cyclic AMP participates in the activation of protein kinase $\mathrm{A}$ to begin the phosphorylation of specific enzymes used in the glucose synthesis. By blocking its removal, caffeine intensifies and prolongs the effects of epinephrine and epinephrine-like drugs. ${ }^{11,13}$ Cyclic AMP also directly increases heart rate, and caffeine increases the metabolic rate and oxygen consumption. ${ }^{14}$ Methylxanthines increase energy expenditure independently of physical activity and also enhance carbohydrate utilization in the infant. ${ }^{9}$ Studies have suggested that caffeine also reduced splanchnic blood flow in the neonatal gut. ${ }^{15}$ Caffeine is a diuretic and is based on the differential expression of adenosine A1 receptors. Caffeine increases glomerular filtration (causing diuresis) through action on afferent arteriole and reduces sodium reabsorption (causing natriuresis) at the level of proximal tubules. $^{16-18}$ In baboon models with prematurity and respiratory distress, caffeine was associated with a doubling of urine output. ${ }^{19}$ The abovementioned mechanisms of action cumulatively contribute to the catabolic effects of caffeine during the neonatal period and thus negatively influence the weight gain.

While caffeine has respiratory benefits for preterm infants, it may have adverse molecular and cellular effects on the developing brain. ${ }^{20,21}$ Half-life of caffeine varies widely among infants based on their liver function status, exposure to certain concurrent medications, and the level of hepatic enzymes needed for metabolism. Among healthy adults, caffeine's half-life is $\sim 4.9$ hours and in pregnant women 9-11 hours. ${ }^{8}$ Among infants and children, half-life is longer and for newborn infants could be up to 30 hours and as per a more recent study, the mean caffeine half-life was $87 \pm 25$ hours at $35 \pm 1$ week postmenstrual age. ${ }^{22}$

Caffeine is metabolized in the liver by the cytochrome P450 oxidase enzyme system (specifically the $1 \mathrm{~A} 2$ isoenzyme) into three forms of dimethylxanthines, each with their own effects on the human body: (1) paraxanthine, (2) Theobromine, and (3) theophylline. They are further metabolized and excreted in urine. ${ }^{11}$ Paraxanthine increases lipolysis, which releases glycerol and fatty acids into blood to be used as fuel by the muscles. Theobromine is a vasodilator that increases the amount of nutrient flow to the brain and muscles. Theophylline acts as a smooth muscle relaxant, however, acts also as a chronotrope and inotrope, increasing heart rate and contractility. ${ }^{13}$

Caffeine through its effect on metabolic rate, diuretic action, hyperglycemic property, and catabolic tendency could influence the short-term growth, especially considering the current practice of prolonged postnatal caffeine therapy for AOP. ${ }^{8,10,23}$ A recent study has suggested an osteopenic effect of caffeine on premature infants and perhaps contributes adversely to the bone growth of extremely low birth weight (ELBW) population as well. ${ }^{24}$ We undertook this retrospective descriptive cohort study with an objective to determine the effects on mean daily weight gain (MDWG) of ELBW and VLBW infants treated with two different oral dosage schedules of $\mathrm{CC}$ for the treatment of AOP [5 mg/(kg·day) vs. $10 \mathrm{mg} /(\mathrm{kg} \cdot$ day $)]$.

\section{Aims}

To recognize and analyze the influence on postnatal weight gain of ELBW (below $1000 \mathrm{~g}$ birth weight) and VLBW (below $1500 \mathrm{~g}$ birth weight) infants exposed to two dosage regimens of oral $\mathrm{CC}$ for the management of AOP. To highlight the importance of growth monitoring and nutritional supplementation of premature infants exposed to prolonged duration of oral CC during a vulnerable period of critical somatic growth.

\section{Methods \\ Patient population}

This study was carried out in the NICU of University Maternity Hospital Limerick (UMHL), Ireland, between January 2002 and December 2016. Our maternity hospital has an in-birth rate approximating 5000 per year from a fairly fixed Caucasian population (ethnic minorities accounting for $<10 \%$ of antenatal booking) with an antenatal steroid uptake of $91 \%$ for the eligible population. Our expressed breast milk exposure (mother's own milk or donor breast milk) for the VLBW infants was $40 \%$ in $2005,80 \%$ in 2012 , and $91 \%$ in 2016. For the ELBW infants, breast milk use steadily increased from $20 \%$ in 2005 to $90 \%$ in 2012 and through a quality improvement project reached $100 \%$ from 2014 to $2016 .{ }^{21}$ Inclusion criteria were (1) ELBW and VLBW infants born in our 
hospital during the study period with birth weight of $<1500 \mathrm{~g}$ and gestational age of 23-30 weeks, and (2) infants requiring treatment with oral $\mathrm{CC}$ for AOP. Exclusion criteria were (1) infants born with major congenital anomalies, (2) infants concurrently receiving other medicines that could influence weight gain such as diuretics, ibuprofen, indomethacin, or postnatal corticosteroids, (3) infants transferred in/out of the unit from/to other neonatal centers, (4) infants with blood culture-proven sepsis during the course of oral caffeine treatment, (5) grade 3/4 intraventricular hemorrhage (IVH), (6) infants on fluid restriction, (7) infants who have received middle of the dosage range of $7-8 \mathrm{mg} /(\mathrm{kg} \cdot$ day) of CC from the treating team, (8) infants with necrotizing enterocolitis (NEC) with modified Bell's stage $2 \mathrm{~b}$ and above, ${ }^{25}$ and (9) infants while receiving intravenous caffeine. With our unit's enhanced breast milk uptake for the prevention of NEC, there was a significant reduction of confirmed NEC in the second half of the study period (12 in 2002-2008 and 4 in 2009-2016 period). Intravenous caffeine was the choice for the first few days and was converted to oral route subsequently when tolerating sufficient nasogastric feeds. Infants who were initially on intravenous CC and subsequently converted to oral caffeine were included in the study. Those who did not initially receive intravenous caffeine, however, subsequently required oral caffeine during days 14-28 or 29-56 days, were also included in the study.

We did not exclude infants based on maternal caffeine/ tobacco exposure and no data were collected in this regard. Infants were not excluded based on enteral versus parenteral route of nutrition, type of enteral feeding, or caloric/protein concentration of the feeds used. During the study period, powdered cow's milk-based milk fortifier was used when infants reached $100 \mathrm{~mL} / \mathrm{kg}$ of breast milk intake. We acknowledge that the use of breast milk fortifier or the universal use of donor breast milk was not established in our unit during the 2002-2010 period. Contribution by SGA within the study population was not separately analyzed.

\section{Data sources}

Study variables were obtained from the manually entered neonatal drug kardex (drug prescription charts), serially recorded weight chart from the nursing notes, demographic characteristics collected from the patient admission record in NICU, annually collated and submitted data toward the VON (Vermont Oxford Network) international benchmarking of all infants below $1500 \mathrm{~g}$ birth weight, hospital inpatient enquiry data, and the computerized patient admission system.

\section{Intervention and outcome measurement}

Infants during the study period were treated with two different dosing regimens: (1) $5 \mathrm{mg} /(\mathrm{kg} \cdot$ day) dose of $\mathrm{CC}$ equivalent to $2.5 \mathrm{mg} /(\mathrm{kg} \cdot$ day) caffeine base and (2)
$10 \mathrm{mg} /(\mathrm{kg} \cdot$ day $)$ dose of CC equivalent to $5 \mathrm{mg} /(\mathrm{kg} \cdot$ day $)$ caffeine base. This resulted from the local guidelines based on published dosage schedules that recommended $5-10 \mathrm{mg} /(\mathrm{kg} \cdot$ day $)$ of CC as the maintenance dose after the initial loading of $20 \mathrm{mg} / \mathrm{kg} .^{5,6,10}$ The decisions on dose and duration of treatment were made entirely by the neonatal teams responsible for the care of the infants. There were no significant changes in our senior medical faculty during the study period. Our unit used oral CC $50 \mathrm{mg} / 5 \mathrm{~mL}$ (equivalent to caffeine base of $25 \mathrm{mg} / 5 \mathrm{~mL}$ ), ML number 0427-01, Rosemount Pharmaceuticals ${ }^{\circledR}$ Ltd. (Leeds, United Kingdom), during the first half of study and a specifically licensed product for neonatal use (Peyona ${ }^{\circledR}$, CC $20 \mathrm{mg} / \mathrm{mL}$ oral solution by Chiesi Ltd.) during the second half.

Weight gain/loss in all infants admitted to the neonatal unit, including those enrolled in our study, was routinely measured three times weekly from birth to discharge by experienced neonatal nursing staff. More frequent weight checks were done if clinically indicated. For the purposes of this study, MDWG in $\mathrm{g} /(\mathrm{kg} \cdot$ day) was calculated for eligible infants between two specific time periods: (1) day of life 14-28 and (2) day of life 29-56. We chose to collect data on recorded MDWG only from day 14 of life, as many of the ELBW and VLBW infants often physiologically lose weight during the first week after birth (mean weight loss of $14 \%$ in the first 6 days) and often start regaining weight only from the second week of postnatal life. ${ }^{26}$ Analysis of other adverse effects of caffeine therapy or measuring serum levels of caffeine was not conducted as part of our study. ${ }^{27}$

\section{Outcome analysis}

For purposes of analysis, we also recorded the patient characteristics - gestation at birth, birth weight, duration and mode of ventilatory support, duration and dose of supplemental oxygen, and the $\mathrm{kcal} / \mathrm{kg}$ of caloric nutritional intake and $\mathrm{g} / \mathrm{kg}$ of nutritional protein intake (via enteral or parenteral nutrition). We tabulated our results using Microsoft Excel and statistical analysis was done with SPSS version $23\left(\right.$ SPSS $^{\circledR}$, Chicago, IL).

\section{Ethical consideration}

Study was approved by the University Maternity Hospital Audit Committee. Standard sets of clinical data from infants were included in our study, were collected anonymously, and infants were not exposed to placebo, novel intervention, or new dosage regimen.

\section{Results}

\section{Study infants}

During the 15-year study period, a total of 457 ELBW and VLBW infants were exposed to CC. Among the 14-28-day group, after applying the exclusion criteria, 
Table 1. Baseline Characteristics of Premature Infants Exposed to Caffeine Citrate at Two Different Doses

\begin{tabular}{|c|c|c|c|c|c|c|}
\hline \multirow{2}{*}{$\begin{array}{l}\text { Days of treatment } \\
\text { Dose of } \mathrm{CC}, \mathrm{mg} /(\mathrm{kg} \cdot \mathrm{day})\end{array}$} & \multicolumn{2}{|c|}{ 14-28 days } & \multirow[t]{2}{*}{$\mathrm{p}$} & \multicolumn{2}{|c|}{$29-56$ days } & \multirow[t]{2}{*}{$\mathrm{p}$} \\
\hline & 5 & 10 & & 5 & 10 & \\
\hline$n$ & 248 & 170 & & 214 & 118 & \\
\hline Birth weight, $g$ & $1074 \pm 418$ & $1002 \pm 426$ & 0.318 & $998 \pm 480$ & $1010 \pm 442$ & 0.229 \\
\hline SIMV/PTV/HFOV, days & $24 \pm 18$ & $22 \pm 14$ & 0.476 & $20 \pm 17$ & $22 \pm 14$ & 0.440 \\
\hline NCPAP/HFT, days & $28 \pm 16$ & $32 \pm 12$ & 0.270 & $30 \pm 18$ & $34 \pm 14$ & 0.440 \\
\hline Kcal/kg & $116 \pm 18$ & $120 \pm 26$ & 0.158 & $118 \pm 22$ & $122 \pm 24$ & 0.153 \\
\hline Supplemental oxygen, days & $22 \pm 12$ & $18 \pm 10$ & 0.157 & $38 \pm 20$ & $36 \pm 13$ & 0.610 \\
\hline
\end{tabular}

Variables are given as mean \pm standard deviation.

CC, caffeine citrate; HFOV, high-frequency oscillatory ventilation; HFT, high-flow humidified oxygen therapy; NCPAP, nasal continuous positive airway pressure; PTV, patient-triggered ventilation; SIMV, synchronized intermittent mandatory ventilation.

418 qualified for the analysis. Among them, 248 received $5 \mathrm{mg} /(\mathrm{kg} \cdot$ day $)$ and $170 \mathrm{received} 10 \mathrm{mg} /(\mathrm{kg} \cdot$ day $)$ of CC. Among the 29-56-day group, a total of 362 infants were identified and after applying the exclusions, 332 patients who fulfilled the entry criteria were included [214 on the $5 \mathrm{mg} /(\mathrm{kg} \cdot$ day $)$ of $\mathrm{CC}$ regimen and 118 on the $10 \mathrm{mg} /(\mathrm{kg} \cdot$ day $)$ regimen]. Baseline characteristics of these infants are summarized in Table 1 and are comparable without statistically significant differences. Table 2 summarizes the neonatal population characteristics over 15 years.

\section{Mean daily weight gain}

When MDWG was calculated for the study population from day of life 14 to 28 , we found a higher rate of increase for the $5 \mathrm{mg} /(\mathrm{kg} \cdot$ day $)$ group compared with the $10 \mathrm{mg} /$ $(\mathrm{kg} \cdot$ day) group $(17.2 \pm 12$ vs. $13.0 \pm 10.2[p=0.04])$. A similar MDWG pattern was observed for the study popula- tion from day of life 29 to 56 as well. The rate of increase in MDWG was higher in the infants on the lower dose $/ \mathrm{kg}$ of $\mathrm{CC}$, that is, the $5 \mathrm{mg} /(\mathrm{kg} \cdot$ day $)$ cohort compared with the $10 \mathrm{mg} /(\mathrm{kg} \cdot$ day $)$ cohort $(15.6 \pm 10.8$ vs. $10.2 \pm 9.8$ $[p=0.011])$. Our findings are summarized in Table 3 .

Our unit only had a relatively small number of infants in the gestation and birth weight category who did not receive $\mathrm{CC}$ treatment during their NICU stay. This perhaps reflects a possible nonrestricted caffeine use in our unit or could be a manifestation of comfort of modern neonatal units to have a relatively liberal caffeine commencement and maintenance policy. Our VLBW and ELBW infants who were never exposed to postnatal caffeine were 157 and after using the exclusion criteria, only 92 infants qualified and $75(81.5 \%)$ were $\geq 1000 \mathrm{~g}$ and $\geq 30$ weeks of gestation at birth. Considering the limited number of infants in this subgroup, further analysis was not done as the derivation of clinical significance from our findings might not be prudent.

Table 2. Perinatal and Neonatal Population Characteristics Over 15 Years and the Trend in the Use of Caffeine Citrate Among Extremely Low Birth Weight and Very Low Birth Weight Infants

\begin{tabular}{|c|c|c|c|c|c|c|}
\hline Year & $\begin{array}{c}\text { Number of ELBW } \\
\text { and VLBW } \\
\text { infants exposed } \\
\text { to caffeinelyear }\end{array}$ & Live births & $\begin{array}{c}\text { Neonatal } \\
\text { admissions }\end{array}$ & $<1000 \mathrm{~g}$ & $1000-1500 \mathrm{~g}$ & Still births \\
\hline 2002 & 19 & 4371 & 757 & 6 & 25 & 26 \\
\hline 2003 & 31 & 4514 & 693 & 16 & 26 & 28 \\
\hline 2004 & 30 & 4418 & 723 & 20 & 17 & 27 \\
\hline 2005 & 29 & 4411 & 688 & 10 & 31 & 28 \\
\hline 2006 & 36 & 4692 & 891 & 16 & 31 & 16 \\
\hline 2007 & 34 & 5153 & 893 & 12 & 43 & 22 \\
\hline 2008 & 28 & 5443 & 995 & 12 & 26 & 30 \\
\hline 2009 & 36 & 5432 & 1087 & 13 & 31 & 24 \\
\hline 2010 & 38 & 5233 & 929 & 17 & 35 & 32 \\
\hline 2011 & 22 & 5137 & 983 & 11 & 16 & 23 \\
\hline 2012 & 34 & 4905 & 906 & 17 & 26 & 22 \\
\hline 2013 & 30 & 4594 & 758 & 13 & 29 & 18 \\
\hline 2014 & 29 & 4522 & 662 & 13 & 23 & 17 \\
\hline 2015 & 33 & 4690 & 761 & 12 & 33 & 24 \\
\hline 2016 & 28 & 4473 & 857 & 10 & 24 & 16 \\
\hline Total & 457 & 71,988 & 12,583 & 198 & 416 & 353 \\
\hline
\end{tabular}

University Maternity Hospital Limerick (UMHL), Ireland 2002-2016.

ELBW, extremely low birth weight; VLBW, very low birth weight. 
Table 3. Mean Daily Weight Gain of Premature Infants Exposed to Caffeine Citrate at Two Different Doses During Two Distinct Time Frames

\begin{tabular}{|c|c|c|c|c|c|c|}
\hline \multirow{2}{*}{$\frac{\text { Days of treatment }}{\text { Dose of } \mathrm{CC}, \mathrm{mg} /(\mathrm{kg} \cdot \text { day })}$} & \multicolumn{2}{|c|}{ 14-28 days } & \multirow[t]{2}{*}{$\mathrm{p}$} & \multicolumn{2}{|c|}{ 29-56 days } & \multirow[t]{2}{*}{$\mathrm{p}$} \\
\hline & 5 & 10 & & 5 & 10 & \\
\hline & 248 & 170 & & 214 & 118 & \\
\hline MDWG, $g$ & $17.2 \pm 12$ & $13.0 \pm 10.2$ & 0.04 & $15.6 \pm 10.8$ & $10.2 \pm 9.8$ & 0.011 \\
\hline
\end{tabular}

MDWG, mean daily weight gain.

\section{Discussion}

Our observation suggests a clinically and statistically significant reduction in the MDWG of a 15 -year retrospective cohort of ELBW and VLBW infants exposed to a higher dose and duration of caffeine for the treatment of AOP. In their original publication, Schmidt et al. observed a greater initial weight loss for premature infants treated with caffeine during the first 3 weeks of life and the trend gradually reduced during the following weeks. ${ }^{5,6}$ However, in our study, the higher dose of maintenance oral caffeine for a prolonged period was associated with a consistent suboptimal weight gain.

Previous studies have demonstrated comparable respiratory benefits from 2.5 to $5 \mathrm{mg} / \mathrm{kg}$ of elemental caffeine and thus as a general maintenance at a higher dose is questionable. ${ }^{6}$ Interestingly, one recent randomized trial suggested that a twice-daily dosage is preferable and another trial recommended that a higher dose could potentially decrease the extubation failure. ${ }^{28,29}$ One prospective cohort study suggested that early commencement of caffeine reduced the need for invasive ventilation and incidence of IVH. ${ }^{30}$ However, a more recent randomized trial did not demonstrate early extubation from early caffeine initiation. ${ }^{31}$ In a postauthorization European trial, routine use of $\mathrm{CC}$ among premature infants was noted to produce up to 21 specific side effects. ${ }^{10}$ Above observations suggest that the use of caffeine among extremely premature infants do warrant vigilance and the dose as well as the duration of treatment should be carefully reviewed and individually tailored. ${ }^{32}$ Our study was not aimed at analyzing the clinical benefits of caffeine based on the initiation time, various doses, or duration of treatment.

Current dosage regimens expose a 25-32-week gestation premature infant to a much higher $\mathrm{mg} /(\mathrm{kg} \cdot$ day $)$ dose than at any other stage in life. A maintenance dose of $5-10 \mathrm{mg} /(\mathrm{kg} \cdot$ day) of CC, often prescribed to $500-1500 \mathrm{~g}$ neonates (equivalent to $150-300 \mathrm{mg} /$ day derived from tea/coffee for a $60 \mathrm{~kg}$ woman during second trimester of pregnancy, assuming comparable pharmacokinetics), is higher than the high level of exposure from dietary caffeine sources during pregnancy quoted in the CARE study and other recent observations. ${ }^{8,33}$ As per a recent systematic review of antenatal caffeine and impact on suboptimal fetal weight gain, existence of a dose-response relationship is suggestive of causation and there is no indi- cation of a threshold effect. ${ }^{34}$ Caffeine with its psychoactive properties influences the sleep cycles and the somatic effects of this property also could modify the weight gain. ${ }^{35}$ Caffeine typically produces prolonged sleep latency, reduces the total sleep time, and worsens the sleep quality. ${ }^{35}$

A few observations from our study with the data spanned over a 15 -year period are worth clarifying. The average weight gain in the younger group (days 14-26) is higher (Table 1) than the group (days 28-56) that is older and expected to be generally gaining more weight. Following clarifications could explain our observed findings: (1) many infants during 14-28 days were still in receipt of total parenteral nutrition or partial parenteral nutrition thus optimizing their nutritional requirement and resultant better weight gain, (2) during the first half of study period, our use of breast milk fortifier was suboptimal, thus affecting the weight gain more among the 29-56 days compared with 14-28 days. As an unexpected observation, our ventilation days (nasal and tracheal combined) are very similar between the two groups (Table 1). We believe that the following could be the contributing factors: (1) The ELBW subgroup had a relatively longer intubation and ventilation and over 28 weeks of gestation was mainly on noninvasive support, (2) as the cohort is over a 15-year period, significant changes in ventilation management and the resultant variations in the duration of mechanical support, (3) those infants included from the first half of the study period perhaps had longer invasive ventilation, (4) contribution by outliers in the 29-56-day groupespecially those with chronic lung disease (CLD).

The relative safety of caffeine compared with other drugs used in the treatment of AOP perhaps makes clinicians less vigilant to limit the duration of treatment of $\mathrm{CC}$, thus leading to unnecessary prolonged exposure with possible side effects. ${ }^{32}$ Recent advances in respiratory support such as nasal continuous positive pressure with facilities for back-up breaths/synchronization, nasal intermittent positive pressure ventilation with additional synchronization, as well as the nasal high-flow humidified oxygen therapy or low-flow systems, all need to be explored further along with postural adjustments and/or changes to infant care procedures, to avoid undue reliance on neonatal caffeine use. It is reassuring to read, from their 11-year follow-up by Schmidt et al., 
that caffeine therapy for AOP did not significantly reduce the combined rate of academic, motor, and behavioral impairments but was associated with a reduced risk of motor impairment. ${ }^{36}$ As per the current evidence, caffeine has a definite role in the management of AOP and perhaps in the reduction of CLD, however, may not be to the extent with which we use it liberally in the current neonatal practice. ${ }^{37}$ Seventy years ago, intramuscular Brandy $0.5 \mathrm{cc}$ was used in newborn infants who failed to breathe, ${ }^{38}$ perhaps our stimulant pharmacotherapy to manage AOP of ELBW infants could 1 day be viewed with a similar surprise and dismay.

\section{Audit process recommendations}

Based on our observations, we have submitted recommendations to the neonatal clinical guideline development group to consider the lower dose of CC at $5 \mathrm{mg} / \mathrm{kg}$ (elemental caffeine of $2.5 \mathrm{mg} / \mathrm{kg}$ ) as the standard starting maintenance dose and to appropriately incorporate additional nutritional input or consideration if ELBW and VLBW infants are maintained on a relatively higher dose of caffeine for prolonged periods. ${ }^{39} \mathrm{~A}$ reaudit is recommended for the audit cycle completion in 2019.

\section{Limitations}

We acknowledge the following limitations: (1) this is a retrospective descriptive observational study and not a randomized trial to make definitive conclusions on causality, (2) treating teams had the freedom to choose the caffeine dose as 2.5 or $5 \mathrm{mg} / \mathrm{kg}$ of elemental caffeine, (3) there is a possibility that treating clinicians might have chosen the higher dose for the "sicker" babies or in whom they have noted persistence of apnea or low caffeine levels on blood tests, (4) even though both groups were exposed to similar feeding regimens, fortifications, and had comparable breast milk uptake, there was no specific monitoring of the calorie or protein intake of the two groups, (5) over the 15-year period of data collection, there were evidence-based changes to various neonatal guidelines and policies that could have a bearing on the weight gain of infants, however, it is unlikely that such confounders only affected one group over the other, (6) we have not done a multiple logistic regression for the statistical analysis, (7) our mean MDWG calculation was derived from thrice-weekly weight checks rather than daily weight measurements; however, this was reflected across both patient groups, (8) two different $\mathrm{CC}$ preparations were used between the first and second halves of the study period, however, previous studies reported comparable clinical effects from both preparations, $^{22}$ (9) observed weight trends were not correlated with the serum concentration of caffeine in the two groups, and (10) we excluded the initial postnatal days when infants were on intravenous caffeine and possibly had a relatively higher physiological weight loss. Com- bining enteral and parenteral routes of $\mathrm{CC}$ in the two study groups would have pharmacokinetic implications. By excluding infants during the parenteral caffeine use, perhaps we indirectly selected infants who are relatively stable in the "growing phase" in both groups thus adding more clinical relevance to our observations.

\section{Conclusion}

While a variety of dietary, ventilatory, and thermoregulatory measures are being optimized to augment postnatal weight gain close to the ideal intrauterine growth curves of ELBW and VLBW infants, not paying sufficient attention to one of the important catabolic agents widely used in the neonatal units around the world is questionable and warrants vigilance from the clinical neonatal community. Additional nutritional supplementation while on caffeine, especially at a higher dosage spectrum, is advisable to be incorporated to the feeding guidelines of units using $\mathrm{CC}$ for prolonged periods for the management of AOP. Our observation is neither powered nor randomized to establish causation, however; the observed association along with the supporting antenatal reports suggests the need for further studies to address this underperceived element of suboptimal postnatal weight gain among premature infants exposed to prolonged caffeine intake.

\section{Compliance with Ethical Statements}

\section{Informed consent}

Not applicable. Anonymous data source access was authorized after University Maternity Hospital Audit Committee approval.

\section{Acknowledgments}

Audit process guidance and quality improvement project (QIP) advice by Ms. Louise Reid, Audit Officer of UMHL, are acknowledged. Appreciation to BMJ rapid response for online acceptance of our response to CARE study group antenatal caffeine exposure in 2008. Contribution by neonatal nursing, midwifery, and medical teams who supported the project over a prolonged period is gracefully acknowledged. No funding support in the data collection, analysis, or preparation of the article.

\section{Authors' Contributions}

R.K.P. recognized the significance of the theme, designed and supervised the study, developed the first draft, and edited the article. A.I. and A.M. collected the patient outcome data and compiled the clinical and demographic variables from the various data sources. M.D. collated the supporting information on ELBW and VLBW population. C.Q. tabulated the clinical characteristics of VLBW and ELBW infants as per the VON submission guidelines. B.M. extracted the prescription 
details of caffeine, dosage regimens, and nutritional intake from neonatal drug prescriptions and edited the pharmacological section. R.K.P. collected and tabulated the perinatal and neonatal population details for the hospital. All authors critically revised the article for important academic content, agreed on the final draft, and approved its submission for publication.

\section{Author Disclosure Statement}

No competing financial interests exist.

\section{References}

1. Finer NN, Higgins R, Kattwinkel J, Martin RJ. Summary proceedings from the apnea-of-prematurity group. Pediatrics. 2006;117(Pt 2):S47-S51.

2. Barrington K, Fine N. The natural history of the appearance of apnea of prematurity. Pediatr Res. 1991;29:372-375.

3. Martin RJ, Abu-Shaweesh JM, Baird TM. Apnoea of prematurity. Paediatr Respir Rev. 2004;5(Suppl A):S377S382.

4. Eichenwald EC, Aina A, Stark AR. Apnea frequently persists beyond term gestation in infants delivered at 24 to 28 weeks. Pediatrics. 1997;100:354-359.

5. Schmidt B, Roberts RS, Davis P, et al. Long-term effects o caffeine therapy for apnea of prematurity. N Engl J Med. 2007;357:1893-1902.

6. Schmidt B, Roberts RS, Davis P, et al. Caffeine therapy for apnea of prematurity. N Engl J Med. 2006;354:21122121.

7. Shrestha B, Jawa G. Caffeine citrate-Is it a silver bullet in neonatology? Pediatr Neonatol. 2017;58:391-397.

8. CARE Study Group. Maternal caffeine intake during pregnancy and risk of fetal growth restriction: A large prospective observational study. BMJ. 2008;337:a2332.

9. Fortier I, Marcouz S, Beaulac-Baillargeon L. Relation of caffeine intake during pregnancy to intrauterine growth retardation and preterm birth. Am J Epidemiol. 1993; 137:931-940.

10. Lista G, Fabbri L, Polackova R, et al. The real-world routine use of caffeine citrate in preterm infants: A European Postauthorization Safety Study. Neonatology. 2016; 109:221-227.

11. Ortweiler W, Simon HU, Splinter FK, Peiker G, Siegert $\mathrm{C}$, Traeger A. Determination of caffeine and metamizole elimination in pregnancy and after delivery as an in vivo method for characterization of various cytochrome $\mathrm{p}-450$ dependent biotransformation reactions. Biomed Biochim Acta. 1985;44:1189-1199.

12. Bolton S, Null G. Caffeine: Psychological effects, use and abuse. Orthomol Psychiatry. 1981;10:202-211.

13. Fisone G, Borgkvist A, Usiello A. Caffeine as a psychomotor stimulant: Mechanism of action. Cell Mol Life Sci. 2004;61:857-872.

14. Stevenson DK. On the caffeination of prematurity. N Eng J Med. 2007;357:1967-1968.

15. Lane AJP, Coombs RC, Evans DH, Levin RJ. Effect of caffeine on neonatal splanchnic blood flow. Arch Dis Child Fetal Neonatal Ed. 1999;80:F128-F129.

16. Spindel E. Action of the methylxanthines on the pituitary and pituitary-dependent hormones. Prog Clin Biol Res. 1984;158:355-363.
17. Williams M, Jarvis MF. Adenosine antagonists as potential therapeutic agents. Pharmacol Biochem Behav. 1988;29:433-441.

18. Fenton RA, Poulsen SB, de la Mora Chavez S, et al. Caffeine-induced diuresis and natriuresis is independent of renal tubular NHE3. Am J Physiol Renal Physiol. 2015;308:F1409-F1420.

19. Yoder B, Thomson M, Coalson J. Lung function in immature baboons with respiratory distress syndrome receiving caffeine therapy: A pilot study. Acta Paediatr. 2005;94:92-98.

20. Atik A, Harding R, De Matteo R, et al. Caffeine for apnoea of prematurity: Effect on the developing brain. Neurotoxicology. 2017;58:94-102.

21. Crealey MR, Ludusan E, Philip RK. Breast milk: The best lovebiotic. J Perinatol. 2015;35:665.

22. Vatlach S, Arand J, Engel C, Poets CF. Safety profile comparison between extemporaneous and a licensed preparation of caffeine citrate in preterm infants with apnoea of prematurity. Neonatology. 2014;105: 108-111.

23. Bauer J, Maier K, Linderkamp O, Hentschel R. Effect of caffeine on oxygen consumption and metabolic rate in very low birth weight infants with idiopathic apnea. Pediatrics. 2001;107:660-663.

24. Ali E, Rockman-Greenberg C, Moffatt M, Narvey M, Reed M, Jiang D. Caffeine is a risk factor for osteopenia of prematurity in preterm infants: A cohort study. BMC Pediatr. 2018;18:9.

25. Stone ML, Tatum PM, Weitkamp JH, et al. Abnormal heart rate characteristics before clinical diagnosis of necrotising enterocolitis. J Perinatol. 2013;33:847-850.

26. Flaherman VJ, Schaefer EW, Kuzniewicz MW, Li SX, Walsh EM, Paul IM. Early weight loss nomograms for exclusively breastfed newborns. Pediatrics. 2015;135: e16-e23.

27. Doyle J, Davidson D, Katz S, Varela M, Demeglio D, DeCristofaro J. Apnea of prematurity and caffeine pharmacokinetics: Potential impact on hospital discharge. J Perinatol. 2016;36:141-144.

28. Faramarzi F, Shiran M, Rafati M, Farhadi R, Salehifar E, Nakhshab M. The efficiency and safety of two different doses of caffeine in respiratory function of preterm infants. Caspian J Intern Med. 2018;9:46-53.

29. Mohammed S, Nour I, Shabaan AE, Shouman B, AbdelHady H, Nasef N. High versus low-dose caffeine for apnoea of prematurity: A randomized controlled trial. Eur J Pediatr. 2015;174:949-956.

30. Borszewska-Komacka MK, Hozejowski R, Rutkowska M, Lauterbach R. Shifting the boundaries for early caffeine initiation in neonatal practice: Results of a prospective, multicenter study on very preterm infants with respiratory distress syndrome. PLoS One. 2017;12:e0189152.

31. Amaro CM, Bello JA, Jain D, et al. Early caffeine and weaning from mechanical ventilation in preterm infants: A randomised, placebo-controlled trial. J Pediatr. 2018; 196:52-57.

32. James JE, Charles B, Philip RK. Caffeine and neonatal apnoea. J Caffeine Res. 2012. DOI: 10.1089/jcr.2012.1218.

33. Greenwood DC, Thatcher NJ, Ye J, et al. Caffeine intake during pregnancy and adverse birth outcomes: A systematic review and dose-response meta-analysis. Eur J Epidemiol. 2014;29:725-734. 
34. James JE. Review: Higher caffeine intake during pregnancy increases risk of low birth weight. Evid Based Nurs. 2015;18:111.

35. Clark I, Landolt HP. Coffee, caffeine, and sleep: A systematic review of epidemiological studies and randomized controlled trials. Sleep Med Rev. 2017;31: 70-78.

36. Schmidt B, Roberts RS, Anderson PJ, et al. Caffeine for Apnea for Prematurity (CAP) Trial Group. Academic performance, motor function, and behavior 11 years after neonatal caffeine citrate therapy for apnea of prematurity: An 11-year follow up of the CAP randomized clinical trial. JAMA Pediatr. 2017;171:564-572.

37. Kua LP, Lee SW. Systematic review and meta-analysis of clinical outcomes of early caffeine therapy in preterm neonates. Br J Clin Pharmacol. 2017;83:180-191.

38. Collis WRF. Modern Methods of Infant Management. London: William Heinemann Medical Books, Ltd.; 1948 pp.158-159.
39. Newkirk M, Shakeel F, Parimi P, et al. Comparison of calorie and protein intake of very low birth weight infants receiving mother's own milk or donor milk when the nutrient composition of human milk is measured with a breast milk analyzer. Nutr Clin Pract. 2018. [Epub ahead of print]; DOI: 10.1002/ncp.10060.

Address correspondence to:

Roy K. Philip, FRCPI, FRCPCH, FJFICMI, MD, MBA

Division of Neonatology

Department of Paediatrics

Graduate Entry Medical School (GEMS)

University of Limerick \& University

Maternity Hospital Limerick

Limerick V94 C566

Ireland

E-mail: roy.philip@hse.ie 